\title{
A criatividade e as situações didáticas no ensino e aprendizagem da matemática
}

\author{
Cleyton Hércules Gontijo \\ Universidade de Brasilia \\ Erondina Barbosa da Silva \\ Secretaria de Estado de Educação do Distrito Federal \\ Universidade Católica de Brasília \\ Rosália Policarpo Fagundes de Carvalho \\ Secretaria de Estado de Educação do Distrito Federal
}

\section{Resumo}

Este artigo propõe uma articulação entre a Perspectiva de Sistemas para o estudo da criatividade, de Csikszentmihalyi, e a Teoria das Situações Didáticas, no campo da matemática, de Brousseau. Consideramos que a articulação das duas teorias possibilita o estudo da criatividade no processo de ensino e aprendizagem da matemática, na medida em que nos permite compreender a ação dos sujeitos, nas situações de aprendizagem, considerando fatores contextuais. Csikszentmihalyi $(1988,1996$, 1999a, 1999b), no estudo da criatividade, e Brousseau (1996a, 2008), no estudo das situações didáticas, integram a ação do sujeito (trabalho do aluno), com o domínio (a situação didática na matemátical e o campo (ação do professor).

Palavras-chave: Educação matemática. Criatividade. Teoria das situações didáticas. 


\section{Creativity and didactical situations in the teaching and learning of mathematics}

This article proposes an articulation between Csikszentmihalyi's Systems Perspective to the study of creativityand Brousseau's Theory of Didactical Situations in the field of mathematics. We believe that the articulation of the two theories enables the study of creativity in the process of teaching and learning mathematics as it allows us to understand the action of subjects in learning situations, considering contextual factors. Csikszentmihalyi (1988, 1996, 1999a, 1999b), in the study of creativity, and Brousseau (1996a, 2008), in the study of didactical situations, integrate the subject's action (the student's work) with the domain (the didactic situation in mathematics) and the field (the teacher's action).

Keywords: Mathematics education. Creativity. Theory of didactic situations.

\section{La creatividad y las situaciones didácticas en la enseñanza y aprendizaje de las matemáticas}

Este artículo propone una articulación entre la Perspectiva de Sistemas para el estudio de la creatividad de Csikszentmihalyi y la Teoría de las Situaciones Didácticas en el campo de la matemática de Brousseau. Consideramos que la articulación de las dos teorías posibilita el estudio de la creatividad en el proceso de enseñanza y aprendizaje de las matemáticas, a medida que nos permite comprender la acción de sujetos, en las situaciones de aprendizaje, considerando factores contextuales. Csikszentmihalyi (1988, 1996, 1999a, 1999b) en el estudio de la creatividad, y Brousseau (1996a, 2008) en el estudio de las situaciones didácticas integran la acción del sujeto (trabajo del alumno), como el dominio (la situación en la matemática) y el campo (acción del profesor).

Palabras clave: Educación matemática. Creatividad. Teoría de las situaciones didácticas. 


\section{Introdução}

Atualmente a área de educação matemática está consolidada e apresenta um considerável referencial bibliográfico, fruto das pesquisas acadêmicas feitas principalmente a partir da década de 1980, quando novos paradigmas para o processo de ensino e aprendizagem da matemática passaram a ser discutidos no mundo inteiro. Boa parte dessa produção bibliográfica é atribuída ao que se tem chamado de didática da matemática francesa (Pais, 2001). Como exemplo, podemos citar a Teoria dos Campos Conceituais, de Gerárd Vergnaud; a Teoria das Situações Didáticas, de Guy Brosseau; os estudos em Engenharia Didática, de Michele Artigue; a dialética ferramenta-objeto, de Regine Douady, entre outros. Trabalhos como os de Parra e Saiz (1996), Machado et al. (1999), Pais (2001), Almouloud (2007), Brousseau (2008) e Vergnaud (2009) têm contribuído para a divulgação dos estudos da didática da matemática francesa no Brasil, por meio de publicações em língua portuguesa.

Muito embora já se tenha uma vasta produção abrangendo os mais diversos temas do campo da educação matemática no cenário brasileiro, poucas são as que tratam do tema criatividade na matemática ou criatividade no processo de ensino e aprendizagem da matemática. Entretanto, na literatura internacional, são encontradas diversas publicações que tratam do desenvolvimento e da avaliação da criatividade em matemática (English, 1997; Haylock, 1985, 1986, 1987, 1997; Livne; Livne; Milgram, 1999; Livne; Mann, 2005; Milgram, 2000; Silver, 1985, 1994, 1997; Silver; Cai, 1996; Sriraman, 2004). Estes estudos, além de descreverem o processo criativo em matemática, têm privilegiado a resolução e a formulação de problemas como estratégias didático-metodológicas que possibilitam o desenvolvimento e análise da criatividade matemática.

Entre as poucas referências publicadas no Brasil, destacamos os trabalhos realizados por Dante $(1980,1988)$ e o trabalho de D’Ambrósio (2004), que apresenta um modelo para explicar a criatividade em matemática. No entanto, esses trabalhos não apresentam dados referentes a estudos empíricos realizados pelos autores. Um exemplo de trabalho de investigação empírica realizado no Brasil foi desenvolvido por Gontijo (2007), que teve como objetivo investigar relações entre criatividade, motivação em matemática e criatividade em matemática com estudantes de ensino médio. 0 autor constatou em sua pesquisa que há uma correlação positiva entre criatividade e criatividade em matemática, bem como há correlação positiva ente criatividade em matemática e motivação em relação a esta área.

Para conduzir o estudo, Gontijo (2006a) propôs uma definição de criatividade matemática para a análise da produção dos estudantes, conceituando-a como 
a capacidade de apresentar inúmeras possibilidades de solução apropriadas para uma situação-problema, de modo que estas focalizem aspectos distintos do problema e/ou formas diferenciadas de solucioná-lo, especialmente formas incomuns (originalidade), tanto em situações que requeiram a resolução e elaboração de problemas como em situações que solicitem a classificação ou organização de objetos e/ou elementos matemáticos em função de suas propriedades e atributos, seja textualmente, numericamente, graficamente ou na forma de uma sequência de ações (op. cit, p. 4).

Os resultados da pesquisa de Gontijo (2007) colaboram com os debates no campo da educação matemática, pois, assim como os trabalhos de Tobias (2004) e de Livne e Milgram (2006), sinalizam que estratégias para estimular os estudantes, motivando-os em relação à matemática, e estratégias para o desenvolvimento da criatividade podem favorecer a superação da ansiedade envolvida na aprendizagem desta disciplina, além de quebrar barreiras que impedem o sucesso nesta área. Sheffield (2003), por exemplo, apresenta um conjunto de técnicas de criatividade adaptadas para o contexto do trabalho pedagógico com a matemática, possibilitando ao professor e aos alunos uma nova dinâmica no espaço/tempo de aprendizagem desta disciplina, propiciando a ambos a experiência matemática da criação, da modelação e da explicação dos objetos de estudo.

Considerando a carência de estudos que tratam da criatividade no campo da matemática no cenário brasileiro, debruçamo-nos sobre a Perspectiva de Sistemas para o estudo da criatividade, de Csikszentmihalyi, e a Teoria das Situações Didáticas, do campo da matemática, de Guy Brousseau, na perspectiva de estabelecer articulações entre estas teorias. Para Gontijo (2007), a articulação dessas duas teorias pode oferecer novos elementos ao estudo da criatividade em matemática. Assim, o objetivo central deste trabalho é analisar possíveis articulações entre essas teorias e verificar que elementos podem ser agregados ao estudo da criatividade no processo de ensino e aprendizagem da matemática.

Esperamos que as reflexões aqui apresentadas colaborem com o desenvolvimento de práticas pedagógicas que contemplem a criatividade no campo da matemática, pois os Parâmetros Curriculares Nacionais para os anos iniciais do ensino fundamental (Brasil, 1997, p. 7) estabelecem, entre outros objetivos, que o trabalho com a matemática deve contribuir para que os alunos sejam capazes de

questionar a realidade formulando-se problemas e tratando de resolvê-los, utilizando para isso o pensamento lógico, a criatividade, a intuição, a capacidade de análise crítica, selecionando procedimentos e verificando sua adequação (Grifo nosso). 
Além disso, esses Parâmetros Curriculares Nacionais (Ibid., p. 31) enfatizam que

o ensino de Matemática prestará sua contribuição à medida que forem exploradas metodologias que priorizem a criação de estratégias, a comprovação, a justificativa, a argumentação, o espírito crítico, e favoreçam a criatividade, o trabalho coletivo, a iniciativa pessoal e a autonomia do desenvolvimento da confiança na própria capacidade de conhecer e enfrentar desafios (Grifos nossos).

\section{Os estudos em criatividade}

0 termo criatividade é polissêmico, e não há acordo quanto ao seu significado. No senso comum, há certa concordância de que a criatividade é necessária, sobretudo à vida moderna e ao mundo do trabalho, e que, portanto, a escola precisa favorecer o desenvolvimento de habilidades criativas nos estudantes.

Do ponto de vista das pesquisas acadêmicas, principalmente no campo da psicologia, já existe um consenso de que a criatividade se refere a algo novo, útil e de valor (Fromm, 2003).

A análise dos estudos em criatividade aponta que estes ora estiveram centrados no sujeito, ora na produção criativa, e só muito recentemente passaram a considerar fatores ambientais como determinantes no processo criativo. Para Alencar e Fleith (2003a, p. 2), "para se compreender porque, quando e como novas ideias são produzidas, é necessário considerar tanto variáveis internas quanto variáveis externas ao indivíduo".

Como o interesse do presente estudo é apontar elementos que podem ser agregados ao estudo da criatividade no processo de ensino e aprendizagem da matemática, interessa-nos não o produto criativo ou o sujeito em particular, mas de que forma se articulam o sujeito que aprende, o sujeito que ensina e os saberes matemáticos no processo de produção criativa. Assim, o foco da presente análise é o processo criativo situado em um dado domínio, a matemática, e em determinado espaço, a escola. Nesse sentido, elegemos a Perspectiva de Sistemas, de Csikszentmihalyi, que oferece elementos para se compreender esse processo considerando fatores contextuais, e estamos propondo uma aproximação desta com a Teoria das Situações Didáticas, de Guy Brousseau.

Ressaltamos que Csikszentmihalyi e Brousseau não têm o mesmo objeto de investigação, visto que o primeiro desenvolveu um modelo para estudar a criatividade em diferentes áreas e que o segundo desenvolveu uma teoria que trata de ações de ensino e aprendizagem da matemática. Além disso, ambos conduzem os seus estudos em contextos diferentes e, possivelmente, não conhecem a obra um do outro. 
Entretanto, consideramos que há elementos na produção destes pesquisadores que guardam certa relação entre si e, se articulados, podem favorecer o desenvolvimento de práticas pedagógicas que contribuam no processo de aprendizagem da matemática assim como para o desenvolvimento do potencial criativo dos estudantes nesta área.

\section{A Perspectiva de Sistema e a Teoria das Situações Didáticas: possíveis articulações}

Para Csikszentmihalyi (1988, 1996, 1999a, 1999b), a criatividade não é o resultado apenas de uma ação individual, mas emerge da interação entre indivíduo e ambiente sócio-histórico-cultural. No modelo proposto por esse autor, o estudo e o desenvolvimento da criatividade devem considerar os sistemas sociais, o que implica compreendê-la como um processo resultante da interação dialética entre três sistemas: indivíduo (bagagem genética e experiências pessoais), domínio (cultura e produção acadêmica) e campo (sistema social). Em busca de uma aproximação entre a Perspectiva de Sistema e o ambiente escolar, consideramos que os estudantes fazem parte do sistema "indivíduo", os professores são os representantes do sistema social (campo) e, como constituinte do sistema domínio, tem-se a matemática escolar.

Ressalta-se que o modelo proposto pela Perspectiva de Sistema considera que os indivíduos, o sistema social e o domínio estão em um processo marcado por uma interação dialética, o que implica considerar que as ações dos indivíduos e dos representantes do campo também estão em constante interação, sendo uma afetada pela ação do outro, de modo que os indivíduos, em função de sua produção e ação, podem interferir nos julgamentos dos membros do campo e, assim, introduzir modificações no domínio.

De forma semelhante, entretanto considerando um objeto distinto, Brousseau (1996a), por meio da Teoria das Situações Didáticas, criou um modelo para o estudo da interação entre o aprendiz, o saber e meio (milieu). 0 seu objetivo é modelar situações de ensinoaprendizagem de matemática adequadas para que a ação do aluno viabilize a construção do conhecimento. Nesse sentido, analisa a relação entre aluno-professor-saber por meio de um conjunto de situações que fazem a mediação entre o sujeito e o saber. Também nesta teoria, a interação entre aluno, professor e saber se dá de forma contínua.

Tendo em vista que o foco da Teoria das Situações Didáticas é o processo de ensino e aprendizagem da matemática, esta teoria ganhou visibilidade internacional e é utilizada por muitos professores para orientar a organização do trabalho pedagógico com a matemática. No Brasil, diversos trabalhos apresentaram e discutiram as potencialidades desta teoria (Almouloud, 2007; Freitas, 1999; Pais, 2001; Silva, 1999). 
Entretanto, no que diz respeito aos estudos no campo da criatividade, apesar de a Perspectiva de Sistemas ser aplicada em diversas áreas do conhecimento, no campo da matemática ainda predominam estudos focados na produção de indivíduos considerados talentosos, sem uma análise desta produção articulada com os fatores sociais e culturais. Uma característica marcante nos estudos que envolvem a matemática refere-se à preocupação dos pesquisadores desta área com a busca por diferenciar o que chamam de habilidades acadêmicas e habilidades criativas no processo de resolução e de proposição de problemas. Encontramos trabalhos produzidos em diferentes tempos que relevam essa preocupação, desde os mais antigos, como os de Poincaré (1908/1996, 1911/1995), Hadamard (1954) e Krutetskii (1976), até os mais recentes, como o de Livne e Milgram (2006). De uma forma geral, as habilidades acadêmicas referem-se mais aos procedimentos lógicos, como os de cálculos, argumentação e aplicação de conceitos, e as habilidades criativas referem-se à capacidade de perceber padrões e relações e de apresentar soluções para os problemas, a partir de diferentes estratégias. Uma possível explicação para o predomínio de estudos centrados nas habilidades individuais está em uma tendência ainda forte atualmente, que é a do uso de testes para medir o potencial dos estudantes, no que se refere tanto à criatividade quanto ao domínio de conceitos e procedimentos relacionados à resolução de problemas.

Na busca por articular as duas teorias consideradas neste trabalho, nós nos referiremos a ambas, simultaneamente, tomando como ponto de discussão os sistemas propostos por Csikszentmihalyi.

Iniciaremos discutindo o sistema "indivíduo", que em ambas as teorias exerce um papel importante tanto no processo de aprendizagem quanto no desenvolvimento da criatividade.

0 processo de aprendizagem é analisado por Brousseau por meio de quatro fases diferentes, nas quais o saber tem funções diferentes e o aluno não tem a mesma relação com o saber. Estas fases são interligadas e podem-se observar tempos dominantes de ação, de formulação, de validação e de institucionalização. Essas fases só poderão ser observadas se o aluno se sentir motivado a participar da atividade proposta.

Entendemos que a forma por meio da qual as situações didáticas são apresentadas aos alunos influencia fortemente o significado do saber escolar matemático que este terá. Segundo Brousseau,

uma situação didática é um conjunto de relações estabelecidas explicitamente ou implicitamente entre um aluno ou um grupo de alunos, num certo meio, compreendendo eventualmente instrumentos e objetos, e um sistema educativo (o professor) com a 
finalidade de possibilitar a estes alunos um saber constituído ou em vias de constituição [...] o trabalho do aluno deveria, pelo menos em parte, reproduzir características do trabalho científico propriamente dito, como garantia de uma construção efetiva de conhecimentos pertinentes (Brousseau, 1986 apud Freitas, 1999, p. 67).

A possibilidade de um estudante se envolver com a situação didática planejada e, a partir dela, produzir criativamente cresce se esta fizer sentido para ele. Almouloud (2007) sintetiza as fases propostas por Brousseau para o processo de aprendizagem, indicando o comportamento do aluno em cada uma delas. Segundo este autor, o momento de ação se caracteriza por tentativas espontâneas dos estudantes, "um jogar livre", podendo haver trocas de informações e interações entre alunos e os diferentes recursos disponíveis no meio. Neste momento, os alunos podem mobilizar objetos conhecidos do saber como ferramentas para resolver todo o problema ou pelo menos parte dele. 0 momento da formulação consiste na realização de escolhas com utilização de linguagem não matemática, ocorrendo trocas de informações e a busca por novas, sendo a comunicação necessária para a ação sobre o meio com vistas à resolução do problema em questão. 0 momento da validação é caracterizado pelo uso da linguagem matemática pelo aluno para validar suas ideias, podendo haver interação entre os alunos para julgar a veracidade e a adequação das informações. 0 momento da institucionalização conta com a ação do professor, que orienta acerca do que é importante, ajudando na seleção e explicitação dos conceitos culturalmente aceitos como válidos.

Tal perspectiva nos remete ao processo criativo, que, segundo Torrance (1965 apud Alencar; Fleith, 2003), caracteriza-se na ação do indivíduo que identifica e percebe problemas, deficiências ou lacunas no conhecimento e que busca solucioná-los, apresentando para tanto hipóteses, testando-as até chegar a um bom termo na solução dos problemas. Em relação ao processo criativo, Fleith (2002) afirma que

[...] tão importante quanto a bagagem de informação armazenada é a forma como o indivíduo acessa e processa essa informação. Os indivíduos criativos conectam, de muitas e variadas maneiras (por exemplo, em termos espaciais, verbais etc.) blocos de informações, criando uma rede complexa de associações. Estas combinações de informações são, na maioria das vezes, ricas e idiossincráticas (0p. cit., p. 29).

Apoiadas na obra de Csikszentmihalyi, Alencar e Fleith (2003a), ao tratar do indivíduo e de suas possibilidades para a produção criativa, afirmam que é preciso considerar as características comumente associadas à criatividade, como a curiosidade, o entusiasmo, a motivação intrínseca, a abertura a novas experiências, a fluência e a 
flexibilidade de pensamento e também o seu background social e cultural, pois é pouco provável ser criativo em um domínio em que não se tenha certa relação ou afinidade. Além disso, as autoras afirmam que é importante para o indivíduo

estar inserido em um ambiente que estimule a produção criativa, valorize o processo de aprendizagem, ofereça oportunidades de acesso e atualização de conhecimento, propicie o acesso a mentores e recursos como livros, computadores etc. (Alencar; Fleith, 2003a, p. 6).

Consideram, ainda, que as expectativas familiares, bem como o apoio dado aos estudos, favorecem a produção criativa. Carlton (1959 apud Gontijo, 2007, p. 45), ao tratar especificamente de indivíduos com potencial criativo em matemática, enumera um conjunto de características para descrever esses indivíduos, que inclui sensibilidade estética para observação de padrões e relações matemáticas; capacidade de resolver e elaborar problemas que passam despercebidos por outras pessoas; desejo de trabalhar de forma independente do professor e de outros colegas; prazer de comunicar ideias matemáticas; capacidade de fazer especulações ou elaborar mais de uma hipótese para um problema; prazer em acrescentar algo novo a um conhecimento produzido na sala ou solução diferente a um problema resolvido; prazer em trabalhar com a linguagem matemática; tendência em fazer generalizações; capacidade de visualizar uma solução inteira de uma vez; capacidade de apresentar imaginação ao processo de produção de ideias matemáticas; convicção de que todo problema deve ter uma solução; persistência em encontrar soluções para os problemas; manifestação de tédio em relação às atividades repetitivas; capacidade de realizar várias operações em curto período de tempo, entre outras.

Consideramos que a emergência da criatividade no processo de ensino e aprendizagem da matemática depende da criação de um ambiente propício à atividade matemática, que estimule a curiosidade e possibilite a efetiva ação do sujeito com os objetos matemáticos. No meio escolar, professores e estudantes estão em permanente interação, cuja intencionalidade é, em princípio, a aprendizagem. Essa interação é mediada por um contrato didático (Brosseau, 2008), no qual ficam explícitas ou implícitas as representações sociais dos sujeitos sobre a matemática e o seu processo de ensino e aprendizagem. Essas representações vão determinar as ações dos sujeitos e vão orientar o engajamento destes no trabalho desenvolvido. Ressalta-se que

a representação social - as concepções, os mecanismos e as dimensões [...] - é uma das perspectivas de entendimento da elaboração e da veiculação de conceitos lafirmações, explicações) e imagens da 'realidade', como os sujeitos a percebem e constroem (Rangel, 1999, p. 48). 
Segundo Rangel (1999), o processo de constituição de uma representação social interessa à didática, pois esta se ocupa das relações entre professores, alunos, conteúdos, formas e contextos de ensino, portanto essas representações repercutem no trabalho pedagógico desenvolvido nas escolas.

Do ponto de vista da didática matemática, é preciso considerar que professores e estudantes realizam trabalhos de natureza diferente, mas complementares. De acordo com Pais (2001, p. 35), “o trabalho do aluno não é diretamente comparável ao trabalho do matemático ou do professor. Mesmo assim, essas atividades guardam correlações cuja análise é de interesse da didática".

Ainda que o trabalho do aluno não seja semelhante ao trabalho do matemático ou do professor de matemática, para que haja a emergência da criatividade é preciso estimular o aluno a redescobrir os conceitos, a reconstruir procedimentos, a expressar-se livremente, a argumentar, a comunicar suas ideias e trocá-las com seus colegas e com os professores. É preciso que o estudante seja estimulado a resolver problemas que tenham significado para ele e que, de alguma forma, se aproximam ao trabalho realizado pelo matemático. Para que isso aconteça, o contrato didático que rege as relações entre estudantes, professores e saber escolar precisa garantir a efetiva ação do estudante.

Consideramos que os aspectos destacados em relação ao sistema "indivíduo", tanto na perspectiva da Teoria das Situações Didáticas quanto na Perspectiva de Sistemas para a criatividade, articulam-se ao mostrar que o papel ativo do estudante no desenvolvimento das situações didáticas propostas pode favorecer não só a aprendizagem e a construção do conhecimento, mas, além disso, a consecução criativa nesse processo, podendo gerar novos procedimentos para a resolução de problemas, algoritmos alternativos e atitudes positivas diante da atividade matemática.

0 segundo fator é o domínio; no caso em discussão, a matemática escolar. Alencar e Fleith (2003a, p. 6), ao analisar este sistema na obra de Csikszentmihalyi, dizem que “o domínio consiste de um conjunto de regras e procedimentos simbólicos estabelecidos culturalmente, ou seja, conhecimento acumulado, estruturado, transmitido e compartilhado em uma sociedade ou por várias sociedades".

Em sentido amplo, podemos dizer que o nosso domínio é o corpo de conhecimentos matemáticos historicamente construídos, no entanto, cabe aqui uma diferenciação entre a matemática, saber científico, e o corpo de conhecimentos com o qual a escola trabalha, aqui denominado de matemática escolar, que será, de fato, considerado como o domínio em questão.

Segundo Pais (2001), o saber científico está relacionado à vida acadêmica, aos saberes produzidos pelas universidades e centros de pesquisa, segundo uma linguagem codificada e formal. Já o saber escolar é constituído pelos saberes e práticas partilhados 
por uma determinada comunidade, sendo os conteúdos matemáticos previstos na estrutura curricular e apresentados por meio de programas de ensino e livros didáticos.

Fiorentini e Lorenzato (2006) contribuem para esclarecer essa diferenciação quando discutem os papéis do matemático e do educador matemático no processo de ensino e aprendizagem. Segundo esses autores, o matemático "tende a conceber a matemática como um fim em si mesma" (2006, p. 3), suas práticas visam ao desenvolvimento da matemática e à formação de pesquisadores, por isso, educam "para a matemática". Já os educadores matemáticos concebem a matemática como meio, e não como fim. A matemática é instrumental para a formação humana e, por isso, educam "pela matemática". Na perspectiva daqueles autores, o matemático trabalha com o saber científico e o educador matemático trabalha com o saber escolar.

Para Muniz (2008), não é possível conceber a ideia de transmitir aos alunos o saber matemático como ele é trabalhado no âmbito científico. 0 autor se fundamenta no conceito de transposição didática, de Chevallard (1991), para dizer que na educação básica não se deve trabalhar a matemática tal qual é tratada em níveis superiores, o que requer dos responsáveis e envolvidos no processo escolar uma transformação desse saber matemático, que cabe também ao professor, adequando-o aos interesses, necessidades e possibilidades de apropriação pelo aluno.

Por meio da transposição didática, isto é, "do trabalho que faz de um objeto de saber a ensinar, um objeto de ensino" (Chevallard, 1991, p. 39), os conhecimentos que constituem o domínio da matemática se tornam acessíveis aos estudantes. Entretanto, este processo de transposição muitas vezes não é concretizado pelos professores em suas práticas pedagógicas, pois estas estão marcadas por representações sociais acerca do que vem a ser o conhecimento matemático e de como se ensina e se aprende matemática. Essas representações foram construídas em um longo período de tempo a partir das concepções, crenças, valores e atitudes que regem a produção de saberes científicos. Assim, as práticas pedagógicas e, consequentemente, as situações de aprendizagem sofrem forte influência das práticas e procedimentos do domínio da matemática científica.

A validação do saber científico está ligada aos paradigmas internos da matemática, enquanto a validação do saber escolar está vinculada ao contrato didático que rege a relação professor-aluno. Quando esse contrato didático está centrado na transmissão do saber matemático científico pelo professor, a validação das produções dos estudantes também sofre forte influência desse domínio, comprometendo também a produção criativa dos mesmos.

Observamos que a cultura e a produção científica, tratadas na Perspectiva de Sistemas e o saber, tratado na Teoria das Situações Didáticas, devem estar acessíveis 
aos alunos para que possam interagir com determinados objetos de estudo, tanto para a apropriação destes como para produzir modificações nos mesmos de modo a incorporá-las no domínio da matemática escolar. Para Freitas (1999, p. 66), “quando o conteúdo matemático é apresentado isoladamente do mundo do aluno, torna-se desprovido da verdadeira expressão educativa. Sem esse vínculo com a realidade, fica impossível possibilitar um processo autêntico de transformação pela aprendizagem" e, acrescentamos, fica impossível criar novos elementos ou abordagens para os conteúdos matemáticas que fazem parte do universo dos alunos.

0 terceiro fator é o campo que, de acordo com Csikszentmihalyi (1988), envolve os especialistas de uma área do conhecimento ou domínio. Cabe a esses especialistas a decisão sobre as mudanças no domínio. Assim, ideias, procedimentos ou conteúdos para serem incorporados a determinada área passam pela avaliação e validação do campo ou dos especialistas dessa área.

No caso de o domínio ser a matemática científica, o campo é constituído pelos pesquisadores que integram os grupos de pesquisas acadêmicas, por instituiç̃̃es que agregam especialistas da área, como a Sociedade Brasileira de Matemática - SBM, por exemplo. Mas, se o domínio é a matemática escolar, o campo é constituído basicamente pelos professores de matemática. Segundo Gontijo (2007, p. 43), “eles representam os especialistas que organizarão as atividades que possibilitarão aos estudantes a experiência matemática e ao mesmo tempo serão avaliadores de suas produções". Assim, para a produção matemática de um estudante ser considerada criativa, ela passará pela avaliação e validação do professor, que, conforme já foi dito, age segundo as suas concepções, crenças, valores e atitudes.

Para que a produção matemática do aluno possa consolidar-se em aprendizagem e expressar a sua criatividade, faz-se necessário que o trabalho pedagógico desenvolvido nas escolas estimule os alunos. Para Brousseau (1996b), é tarefa do professor buscar a situação apropriada que se constitua em situação de aprendizagem. Nesse processo, o professor deve considerar que a resposta do aluno diante da situação não é o que se deseja ensinar, até porque, se fosse, não seria uma situação de aprendizagem.

Segundo essa abordagem, “o professor deve efetuar não a simples comunicação de um conhecimento, mas a devolução de um bom problema" (Freitas, 2002, p. 68). A devolução é uma condição fundamental, significando o aceite pelo aluno da responsabilidade pela busca da solução da atividade proposta, assim como pelo entendimento que o professor elaborou uma situação que ele é capaz de resolver de acordo com os seus conhecimentos prévios. Quando essa devolução é feita, a situação proposta se transforma no problema do aluno.

No processo de resolução de problemas, o estudante tem a possibilidade de mobilizar seus conhecimentos de muitas e variadas maneiras se o contrato didático assim o 
permitir, se a matemática não for tomada como um conjunto fechado de teoremas, postulados e axiomas a serem memorizados pelos alunos e se o professor se colocar como aquele que valida diferentes procedimentos dos alunos e os institucionaliza (Brosseau, 2008). De acordo com Brousseau (1986 apud Silva, 1999), o contrato didático caracteriza-se pelo

conjunto de comportamentos do professor que são esperados pelos alunos e o conjunto de comportamentos do aluno que são esperados pelo professor. [...]. Esse contrato é o conjunto de regras que determinam, uma pequena parte explicitamente mas sobretudo implicitamente, o que cada parceiro da relação didática deverá gerir e aquilo que, de uma maneira ou de outra, ele terá de prestar conta perante o outro (Op. cit, p. 43).

Nesse sentido, o contrato didático rege a relação do professor com o aluno e o saber matemático. Em razão disso estamos considerando que a produção criativa do aluno será fortemente influenciada pelas cláusulas explicitas e implícitas do contrato didático. Ainda hoje, a maioria das práticas pedagógicas em matemática é centrada na transmissão dos saberes pelos professores e na recepção destes pelos estudantes. 0 contrato didático, neste caso, prevê um papel ativo para o professor e um papel passivo para o aluno. Cabe ao aluno memorizar definições, reproduzir algoritmos tidos como universais e procedimentos lógicos que são ensinados pelo professor. A ação do aluno - e, consequentemente, a sua produção criativa - é limitada por esse contrato didático.

Silva (1999, p. 47) diz que o contrato didático se manifesta principalmente quando o mesmo é transgredido por um dos sujeitos da relação pedagógica. Assim, se em vez de assumir o papel de transmissor de saberes o professor propõe situações didáticas em que o aluno sucessivamente, por aproximações, vai construindo o conhecimento, essa lógica é subvertida e o contrato didático exigirá sucessivas renegociações. Nesse caso, a ruptura do contrato didático, do nosso ponto de vista, representa a possibilidade de criação de um ambiente que favoreça a emergência da criatividade em matemática.

De fato, o professor precisa compreender a importância de estimular a criatividade, e a criatividade em matemática. Para Pais (2001, p. 71),

várias situações previstas na educação matemática se iniciam com escolha de um problema considerado compatível com o nível intelectual do aluno. Para que amplie as possibilidades de sucesso dessa escolha é preciso que o professor tenha clareza quanto aos procedimentos que se espera do aluno.

É bem verdade que instituições que congregam professores que ensinam matemática, como a Sociedade Brasileira de Educação Matemática - SBEM, ou instituições 
que trabalham na formação de professores podem influenciar o processo de validação da produção do estudante, na medida em que fazem circular representações sociais positivas em relação à matemática e ao seu processo de ensino e aprendizagem.

A breve discussão apresentada a partir dos sistemas propostos por Csikszentmihalyi nos motiva a afirmar que há uma aproximação entre as duas teorias apresentadas. A articulação destas teorias possibilita o estudo da criatividade no processo de ensino e aprendizagem da matemática, na medida em que nos auxilia a compreender a ação dos sujeitos dentro das situações de aprendizagem, considerando fatores contextuais. Csikszentmihalyi $(1988,1996,1999$ a, 1999b) no estudo da criatividade - da mesma forma que Brousseau (1996a, 2008) no estudo das situações didáticas -, integra a ação do sujeito (trabalho do aluno), com o domínio (a situação didática na matemática) e o campo (ação do professor).

\section{Considerações finais}

No presente artigo discutiu-se possíveis articulações entre a Perspectiva de Sistemas para estudo da criatividade de Csikszentmihalyi e a Teoria das Situações Didáticas de Guy Brousseau, com o objetivo de verificar que elementos podem ser agregados ao estudo da criatividade no processo de ensino e aprendizagem da matemática. Consideramos que as duas teorias, juntas, permitem compreender de maneira mais ampla o engajamento dos sujeitos na atividade matemática e, consequente, o processo criativo como um todo, incluindo aí os procedimentos dos alunos na resolução e proposição de problemas, seus algoritmos alternativos e seus comportamentos diante da atividade matemática. Também possibilitam compreender a criatividade do professor no trabalho de proposição das situações didáticas, de transposição didática e de validação da produção criativa dos alunos. Nesse sentido, outro elemento que se agrega a esse estudo é o contrato didático estabelecido entre professores, estudantes e conteúdos matemáticos.

No entanto, são necessários estudos adicionais a respeito de como o contrato didático pode favorecer ou limitar a atividade criativa do aluno. Desta forma, os efeitos didáticos de que fala Brousseau (2008) podem ajudar a compreender o processo criativo dos alunos e a ação dos professores. Nesse sentido, deve-se incentivar os professores na promoção de um ambiente adequado para o aprendizado da matemática e consequentemente para o desenvolvimento da criatividade nesta área. Gontijo destaca que “é desejável que o professor encoraje os alunos a inventarem os próprios procedimentos em lugar de lhes mostrar como resolver problemas, criando condições para que os alunos possam inventar muitos modos diferentes de resolver o mesmo problema" (2007, p. 56). 
Para que o professor possa promover situações significativas de aprendizagem, que contribuam de fato para que os alunos exerçam conscientemente a sua cidadania e desenvolvam a sua criatividade, ele deve buscar uma formação contínua. Nesse sentido, Gontijo (2006b, p. 243) postula que "devemos ainda investir na formação dos professores, para que também possam desenvolver a sua criatividade e, assim, estimular o desenvolvimento da criatividade em seus alunos."

É preciso que o professor acredite no potencial do aluno e promova situações didáticas para estimular o desenvolvimento da criatividade de maneira geral e da criatividade matemática em sua sala de aula. Para tanto, é necessário que se efetive uma relação didática em que haja a tomada de consciência do que há de implícito nesta relação com o saber, pois a característica fundamental de uma relação didática reside na existência de assimetria entre as relações que professores e alunos mantêm com os saberes. É preciso que haja a construção de uma comunicação que, mediante o contrato didático, busque descobrir o que favorece ou impede o acesso dos alunos ao conhecimento e o que pode estar bloqueando, ou não, a efetiva aprendizagem desses.

Na mesma direção e sentido, o estudante de qualquer nível de ensino necessita de liberdade de ação para ser criativo, mas esta liberdade não significa atribuir ao professor um papel secundário no processo educativo, muito pelo contrário. Conforme preconiza Brousseau (2008), o papel do professor é central na proposição das situações didáticas. Além disso, em um ambiente propício à atividade criativa, professor e alunos estão engajados em situações de aprendizagem nas quais os conteúdos matemáticos possuem significado social. Desta forma, o contrato didático é permanentemente renegociado para que a produção do aluno, criativa ou não, ganhe visibilidade e assim ocorra a aprendizagem de todos os envolvidos no processo.

\section{Referências}

ALENCAR, Eunice Soriano de; FLEITH, Denise de Souza. Contribuições teóricas recentes ao estudo da criatividade. Psicologia: Teoria e Pesquisa, Brasília, v. 19, n. 1, p. 001-008, jan./abr., 2003a.

.Criatividade: múltiplas perspectivas. Brasília: Editora Universidade de Brasília, 2003b.

ALMOULOUD, Saddo Ag. Fundamentos da didática da matemática. Curitiba: Ed. UFPR, 2007.

BRASIL. Ministério da Educação. Parâmetros curriculares nacionais: matemática (1 $1^{\mathrm{a}}$ a $4^{\mathrm{a}}$ séries). Brasília: MEC/SEF, 1997.

Parâmetros curriculares nacionais: matemática (5ª a 8a séries). Brasília: MEC/SEF, 1998.

BROUSSEAU, Guy. Fundamentos e métodos da didática da matemática. In: BRUN, Jean (Org.). Didática das matemáticas. Lisboa: Instituto Piaget, 1996a, p. 35-113.

.Os diferentes papéis do professor. In: PARRA, Cecilia; SAIZ, Irma (org). Didática da matemática: reflexões psicopedagógicas. Porto Alegre: Artes Médicas, 1996b. 
. Introdução ao estudo da teoria das situações didáticas: conteúdos e métodos de ensino. São Paulo: Ática, 2008.

CHEVALLARD, Yves. La transposition didactique: du savoir savant au savoir ensigné. Grenoble: La pensée Sauvage, 1991.

CSIKSZENTMIHALYI, Mihaly. Society, culture, and person: A systems view of creativity. In: Sternberg, Robert Jeffrey (Org.). The nature of creativity. New York: Cambridge University Press, 1988, p. 325-339. Creativity: Flow and the psychology of discovery and invention. New York: HarperCollins, 1996. Implications of a systems perspective for the study of creativity. In: STERNBERG, Robert Jeffrey. (Org.). Handbook of creativity. New York: Cambridge University Press, 1999a, p. 313-335.

Creativity across the life-span: A systems view. In: COLANGELO, Nicholas; ASSOULINE, Susan

(Orgs.). Talent Development III. Scottsdale, AZ: Gifted Psychology Press, 1999b, p. 9-18.

DANTE, Luiz Roberto. Incentivando a criatividade através da educação matemática. 1980. 247f. Tese (Doutorado em Psicologia da Educação) - Pontifícia Universidade Católica de São Paulo, São Paulo.

.Criatividade e resolução de problemas na prática educativa matemática. 1988. 192f. Tese (Livre Docência em Educação Matemática) - Instituto de Geociências e Ciências Exatas, Universidade Estadual Paulista, Rio Claro.

D’AMBRÓSIO, Ubiratan. Um enfoque transdisciplinar à educação e à história da matemática. In: BICUDO, Maria Aparecida V; BORBA, Marcelo de C. Educação Matemática: pesquisa em movimento. São Paulo: Cortez, 2004.

ENGLISH, Lyn D. The development of fifth-grade children's problem-posing abilities. Education Studies in Mathematics, Netherlands, vol. 34, n. 3, p. 183-217, dez. 1997.

FLEITH, Denise de Souza, Ambientes educacionais que promovem a criatividade e a excelência. Sobredotação, Braga (Portugal), vol. 3, nº 1, p. 27-37, 2002.

FREITAS, José Luiz M. de. Situações Didáticas. In: Machado, Silvia D. A. et al.(org) Didática da Matemática: uma introdução. São Paulo: EDUC, 1999.

FROMM, Erich. 0 que é criatividade. In: ALENCAR, Eunice S; FLEITH, Denise de S. Criatividade: múltiplas perspectivas. Brasília: Editora Universidade de Brasília, 2003.

FIORENTINI, Dario; LORENZATO, Sergio. Investigação em Educação Matemática: percursos teóricos e metodológicos Campinas-SP: Autores Associados, 2006.

GONTIJO, Cleyton Hércules. Resolução e Formulação de Problemas: caminhos para o desenvolvimento da criatividade em Matemática. Anais do Sipemat. Recife, Programa de Pós-Graduação em EducaçãoCentro de Educação - Universidade Federal de Pernambuco, 2006a.

.Estratégias para o desenvolvimento da criatividade em Matemática. Linhas Críticas. Revista da Faculdade de Educação - Universidade de Brasília - UnB, Brasília, v. 12, n. 23, p. 229-244, jul./dez. 2006b.

Relações entre criatividade, criatividade em matemática e motivação em matemática de alunos do ensino médio. Tese (Doutorado em Psicologia) - Universidade de Brasília, Instituto de Psicologia, 2007. HADAMARD, Jacques. The psychology of invention on the mathematical field. Dover: New York, 1954 HAYLOCK, Derek W. Conflicts in the assessment and encouragement of mathematical creativity in schoolchildren. International Journal of Mathematical Education in Science and Technology, Leicestershire, v. 16, p. 547-553, set. 1985. 
. Mathematical creativity in schoolchildren. The Journal of Creative Behavior, Hadley-MA, v. 21, p. 48-59, jan. 1986.

. A framework for assessing mathematical creativity in schoolchildren. Educational Studies ii Mathematics, Netherlands, v. 18, p. 59-74, jan. 1987.

. Recognizing mathematical creativity in schoolchildren. International Reviews on Mathematical Education, Karlsruhe, v. 29, n. 3, p. 68-74, jun. 1997.

KRUTETSKII, Vadim Andreyevich. The psychology of mathematical abilities in schoolchildren. Chicago: The University of Chicago Press, 1976.

LEUNG, Shuk-kwan S. On the role of creative thinking in problem posing. International Reviews on Mathematical Education, v. 29, n.3, p. 81-85, jun. 1997.

LIVNE, Nava. L.; LIVNE, Oren E.; MILGRAM, Roberta. M. Assessing academic and creative abilities in mathematics at four levels of understanding. International Journal of Mathematical Education in Science \& Technology, London, v. 30, n. 2, p. 227-243, 1999.

MILGRAM, Roberta M. Assessing four levels of creative mathematical ability in Israeli adolescents utilizing out-of-school activities: A circular three-stage technique. Roeper Review, Lawrenceville, vol. 22, n. 1, p. 111-116, jan. 2000.

. Academic versus creative abilities in mathematics: two components of the same construct? Creativity Research Journal, New Jersey, v. 18, n. 2, p. 199-212, 2006.

MACHADO, Silvia D. A. et al. (Org.). Didática da Matemática: uma introdução. São Paulo: EDUC, 1999. MANN, Eric Louis. Mathematical creativity and school Mathematics: Indicators of mathematical creativity in middle schools students. 2005. 120f. Tese de Doutorado. University of Connecticut, Storrs, USA.

Creativity: the essence of Mathematics. Journal for the Education of the Gifted, v. 30, n. 2, p. 236-260, 2006.

MUNIZ, Cristiano Alberto. Transposição didática: o professor como construtor do conhecimento. In: BRASIL. Programa de Gestão da Aprendizagem Escolar - Gestar II Matemática: Caderno de Teoria e Prática 1- TP1. Brasília: Ministério da Educação, Secretaria de Educação Básica, 2008.

PAIS, Luis Carlos. Didática da Matemática: uma análise da influência francesa. Belo Horizonte: Autêntica, 2001.

PARRA, Cecilia; SAIZ, Irma (Org.). Didática da matemática: reflexões psicopedagógicas. Porto Alegre: Artes Médicas, 1996.

POINCARÉ, Henry. O valor da ciência. Rio de Janeiro: Contraponto, 1995. Trabalho original publicado em 1911.

A invenção matemática. Em P. Abrantes, L. C. Leal \& J. P. Ponte (Orgs.). Investigar para aprender matemática. Lisboa: Projecto MPT e APM, 1996, p. 7-14. Trabalho original publicado em 1908.

RANGEL, Mary. Das dimensões da representação do "bom professor" às dimensões do processo de ensino-aprendizagem. In: TEVES, Nilda; RANGEL, Mary (Org.). Representação Social da Educação. Campinas-SP: Papirus, 1999, p. 47-77.

SHEFFIELD, Linda J. Using creativity techniques to add depth and complexity to the mathematics curricula. Trabalho apresentado na 3a Asia Regional Conference on Mathematics Education. Shangai, 2005. Disponível em http://euler.math.ecnu.edu.cn/earcome3/sym1/EARCOME3_Sheffield_Linda_Sym1.doc. Acessado em 20/08/2005. 
SILVA, Benedito Antonio da. Contrato Didático. In: MACHADO, Silvia D. A. et al.(org) Didática da Matemática: uma introdução. São Paulo: EDUC, 1999.

SILVER, Edward A. Teaching and learning mathematical problem solving: multiple research perspectives. Hilisdale, NJ: Eribaum, 1985.

On mathematical problem posing. For the Learning of Mathematics, Edmonton, v. 14, p. 1928, fev. 1994.

. Fostering creativity through instruction rich in mathematical problem solving and problem posing. International Reviews on Mathematical Education, Karlsruhe, vol. 29, n. 3, p. 75-80, 1997.

SILVER, Edward A.; CAI, Jinfa. An analysis of arithmetic problem posing by middle school students. Journal for Research in Mathematics Education, Reston, VA, v. 27, p. 521-539, nov. 1996.

SRIRAMAN, Bharath, The characteristics of mathematical creativity. The Mathematics Educator, Athens (Georgia - USA), vol. 14, n. 1, p. 19-34, 2004.

TOBIAS, Sheila. Fostering creativity in the Science and Mathematics classroom. Trabalho apresentado na Conference at National Science Foundation, Malásia. Disponível em <http:/www. Wpi.edu/News/ Events/SENM/tobias.ppt.> Acesso em: 10 set. 2005.

VERGNAUD, Gérard. A criança, a matemática e a realidade. Curitiba: Editora da UFPR, 2009.

Recebido em setembro de 2011.

Aprovado em Janeiro de 2012.

Cleyton Hércules Gontijo, doutor em Psicologia pela Universidade de Brasília. É professor adjunto no Departamento de Planejamento e Administração da Faculdade de Educação da Universidade de Brasília e professor do Programa de Pós-Graduação em Educação na área de Educação Matemática. Publicações recentes: Avaliação da criatividade em Matemática lco-autoria com FLEITH, Denise. In: ALENCAR, Eunice Soriano de; BRUNO-FARIA, Maria de Fátima; FLEITH, Denise de Souza. (Org.). Medidas de criatividade: teoria e prática. Porto Alegre: Artmed, 2010, p. 91-111). E-mail: cleytondunb.br

Erondina Barbosa da Silva, doutoranda em Educação pela Universidade de Brasília. Professora de Matemática da Secretaria de Estado de Educação do Distrito Federal e da Universidade Católica de Brasília. Publicação recente: Educação matemática: uma leitura a partir da memória dos pioneiros lem co-autoria com vários autores. In: PEREIRA, Eva Wairos et al. [orgs.]. Nas asas de Brasília - Memória de uma utopia educativa [1956-1964]. Brasília: Editora UnB, 2011, p. 277-291]. E-mail: erondina@agmail.com

Rosália Policarpo Fagundes de Carvalho, mestre em Educação pela Universidade Católica de Brasília. Professora da Secretaria de Estado de Educação do Distrito Federal. Publicação recente: Educação matemática: uma leitura a partir da memória dos pioneiros lem co-autoria com vários autores. In: PEREIRA, Eva Wairos et al. [orgs.]. Nas asas de Brasília - Memória de uma utopia educativa [1956-1964]. Brasília: Editora UnB, 2011, p. 277-291]. E-mail: rosaliapolicarpođayahoo.com.br 